\title{
CRITICAL DATA UPON THELYTOKY IN SCLERODERMA IMMIGRANS.
}

\section{By Clyde E. KeEler. ${ }^{1}$}

On account of the unusual nature of my results in breeding Scleroderma immigrans, I thought it well to record the evidence pointing toward thelytoky in my specimens. (Psyche, Vol. XXXVI, No. 1, pp. 41-44)

Mr. Bridwell suggested (Psyche, Vol. 36, p. 120) that my F3 females might not have remained virgin, due to the fact that the early hatching males have been known to chew holes into the neighboring cocoons and fertilize their unhatched sisters. The possibility suggested is quite reasonable and makes necessary a more detailed explanation of the results summarized in Table 1 of my former paper.

In this table I did not report the contents of all the vials individually. The data given under F3 as 1 winged $t$, 1 wingless $\hat{o}$, and 12 wingless $q \propto$, consisted of insects born in five separate vials.

Vial No. 1 hatched Aug. 14, 1928. A wingless $\hat{o}$, and a wingless $q$ emerged and were removed from the vial. Later in the day two wingless $q$ \% hatched and were kept virgin.

Vial No. 2 hatched Aug. 27. In this vial was found one wingless $\&$ which was kept virgin.

Vial No. 3 hatched Aug. 29. This vial contained four wingless $q$. They were kept virgin.

Vial No. 4 hatched Sept. 16. In this vial there hatched a single wingless $\%$, which was kept virgin.

Vial No. 5 hatched Sept. 16. In this vial were found 1 winged $\hat{o}$ and 3 winged $q q$. These were mated together.

${ }^{1}$ Research Fellow, Harvard Medical School. 
No other insects could have hidden in the vials undetected because all coccoons in the vials were dissected with forceps at the time of examination.

The two virgin $\& \&$ of vial No. 1 were placed in a separate vial and when the female of vial No. 2 emerged, she was placed with them.

Of the four females in vial No. 3, three were placed in a single vial and the fourth in a separate vial.

The female of vial No. 4 was also given a separate vial.

Mr. Bridwell's objection might be thought to apply to the two virgin females removed from vial No. 1, had I not examined their cocoons for holes when I removed the wingless $\delta$ and the wingless $q$.

But supposing Mr. Bridwell's assumption to be correct in the case of vial No. 1, and, that sperm could have been transmitted through holes in their cocoons too small to be detected with a hand lens, this would throw out only the data obtained from the virgin females of vials Nos. 1 and 2, the offspring of which (born Oct. 31) consisted of 14 wingless females.

Even then, we would be unable to account for the 19 $\circ$ \& from the virgin females born in vials Nos. 3 and 4 in which vials no males occurred.

Errata in previous paper: Table 1, column 4, line 2 (read $\hat{s}$ instead of $q$; line 4 (read 14 instead of 4$)$. 

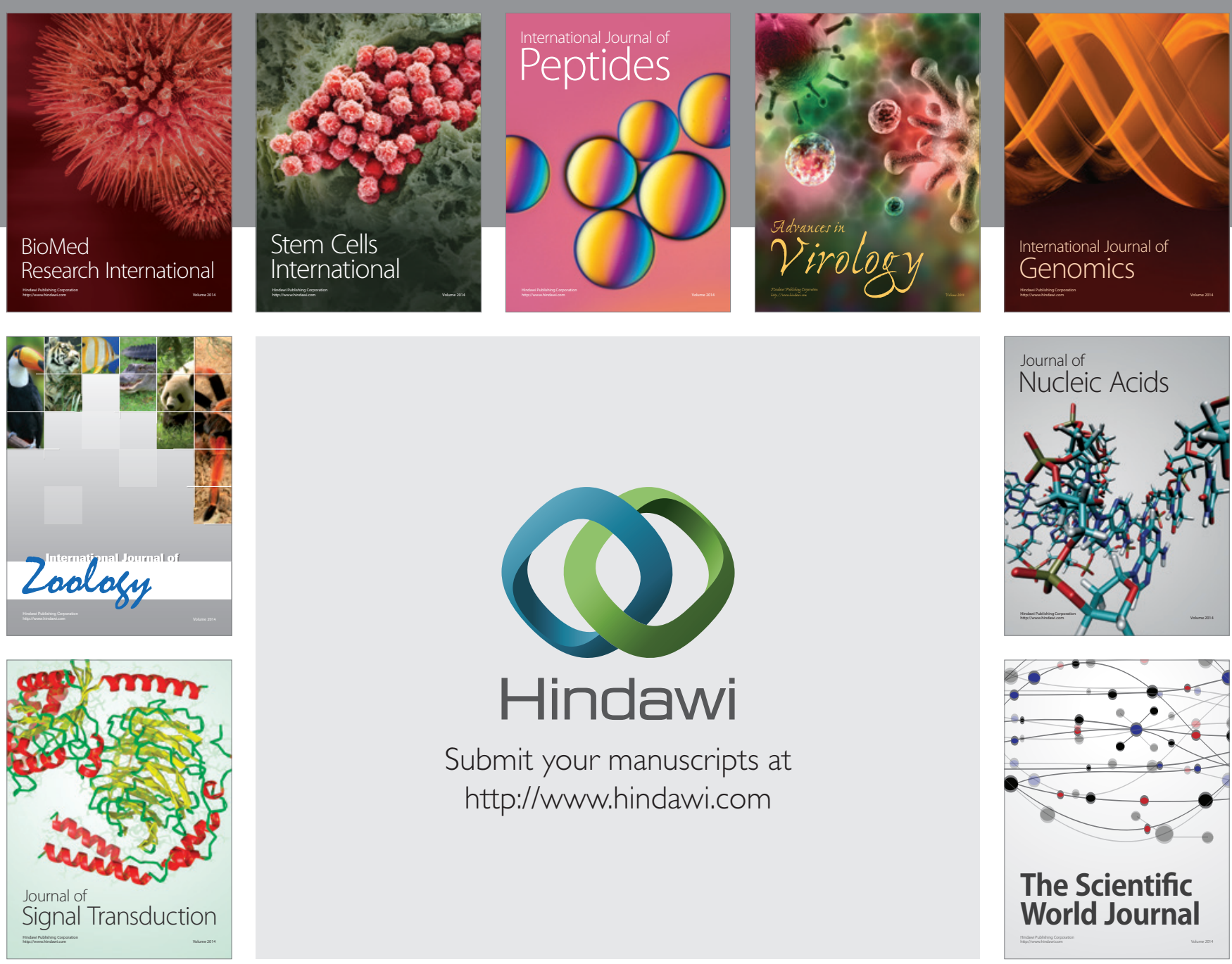

Submit your manuscripts at

http://www.hindawi.com
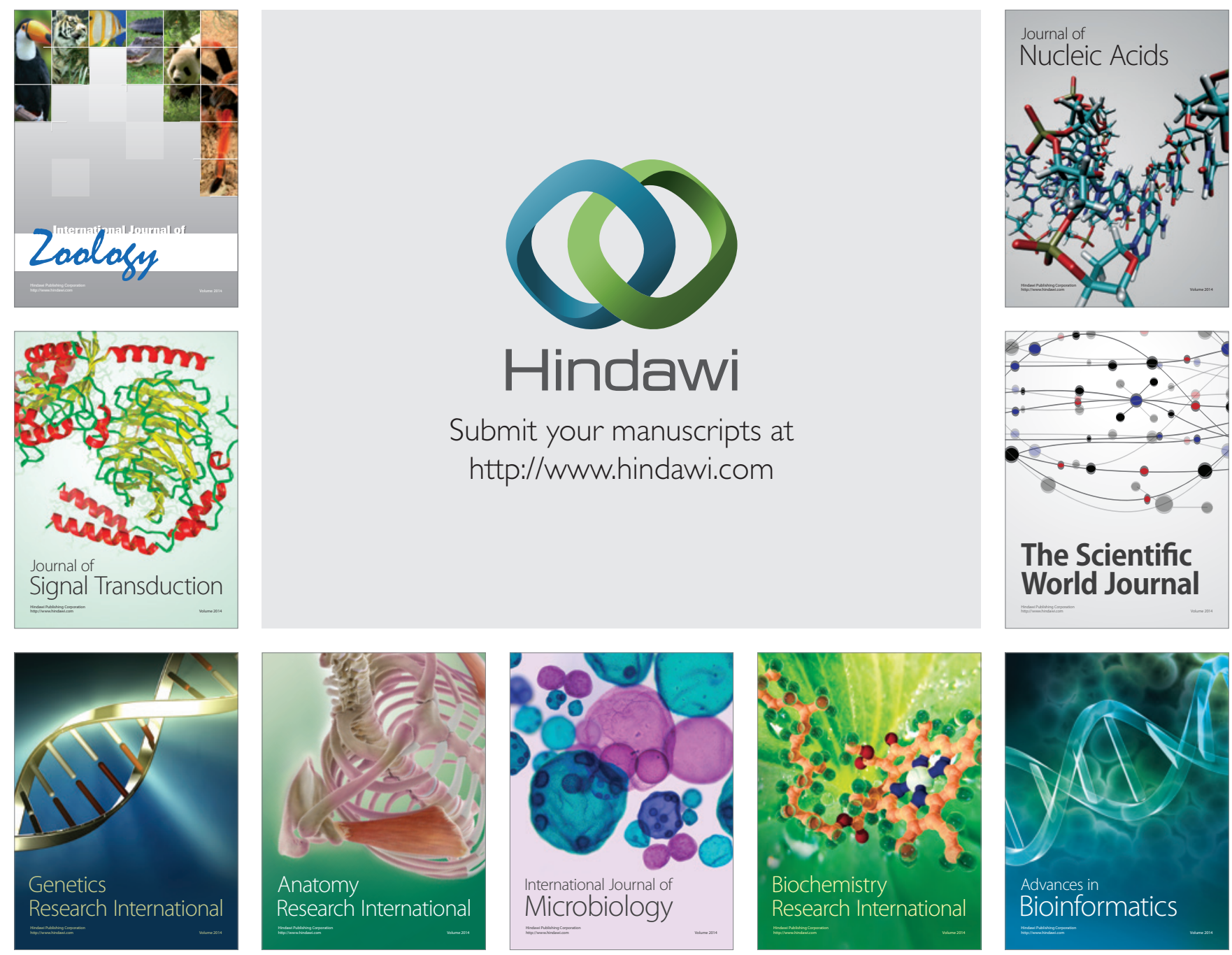

The Scientific World Journal
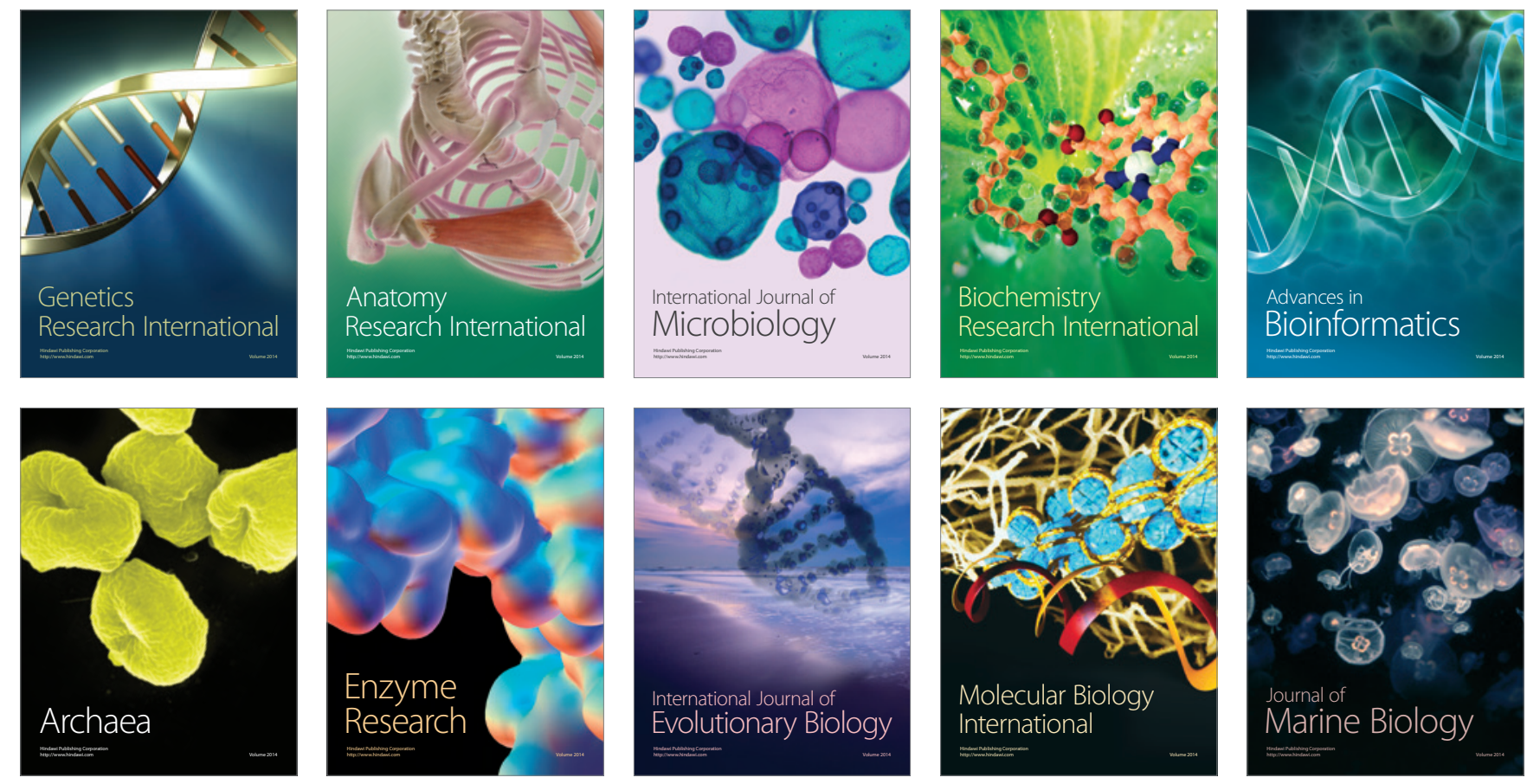